\title{
A Study of Patient's Pain Assessment Based on Facial Expression: Issues and Challenges
}

\author{
Elaf N. Saddam *, Saad Mutashar ${ }^{0}$, Wissam H. Ali $\mathbb{C}$ \\ Electrical Engineering Dept., University of Technology-Iraq, Alsina'a street,10066 Baghdad, Iraq. \\ *Corresponding author Email: eee.19.07@grad.uotechnology.edu.iq
}

\section{H I G H L I G H T S}

- Automatic Pain Recognition (APR) reduces patient overcrowding in healthcare facilities. Especially during the time of epidemics, such as covid-19.

- If the APR is not accepted by the physicians and the rest of the medical staff then this system will not give any chance to develop and obtain experimental results in real life.

- Facial expression presented higher acceptability than other indicators of standing alone as an input signal for the automatic pain recognition system.

- More efforts must be made to collect the data and make it available.

\section{A R T I C L E I N F O}

Handling editor: Ivan A. Hashim

Keywords:

Pain assessment

Pain recognition

Facial expressions

Body movement and vocalization

\begin{abstract}
A B S T R A C T
Pain is considered as an emotional experience and a restless feeling associated with tissue damage. When the interpretation begins in the brain, the sensation of pain occurs; a signal transmitted to the brain through the nerve fiber. Pain helps the body to stop further damage to the tissues. Since there are numerous ways to convey and feel pain, the perception of pain is special to all. Technology that promotes pain assessment is an urgent need to reduce restless feelings and suffering. This paper aims to demonstrate the issues and challenges facing the patient's pain assessment based on facial expression. The design and implementation of an automatic pain recognition system and explain the various concepts relevant to it, such as the type of modalities, the procedure of collection and processing data sequentially to reach the classifier. Then presenting clarification for various signals as input data (facial expressions, body movement, and vocalization). This survey would positively help researchers to supplement their efforts towards the expansion of patients' pain assessment based on facial expression.
\end{abstract}

\section{Introduction}

Pain is an unavoidable experience that a person must go through at some stage of his/her life. The most broadly agreeable definition of pain refers to an unpleasant sensory and emotional experience associated with actual or potential tissue damage or described in terms of such damage [1]. Recently, extensive research has been conducting to realize the concept of pain, which is a uniquely individual experience, a mental event [2]. In general, the pain is either acute or chronic. Acute pain is a type of pain that usually lasts less than 3 to 6 months or pain that directly related to soft tissue damage, such as sprained ankles or paper cuts [3]. It is short-lived, gradually resolves as the wounded tissue heals. Acute pain is distinct from chronic pain and is relatively sharper and more severe.

Chronic pain is a kind of pain that lasts more than three months. This pain may gradually worsen and recur intermittently, surpassing the usual healing process. After wounded tissue, regeneration of pain expected to stop once the underlying issue is treating. However, chronic pain may remain of no evident biological cause after healing injuries. In addition, it can cause considerable psychological and emotional distress, often limiting the ability of the individual to function fully. Uncontrolled pain leads to various problems and in many aspects of life, not only in personal health [4]. However, it also affects the social life [26] and the economies of a country because of the costs of treatment and continuous checks in addition to the rest periods needed by people who are suffering from pain [5]. 
Permanent pain syndrome is a highly expected result of untreated pain [6]. Oftentimes associated with impaired immunity, reduced mobility, sleep disturbances, decreased concentration, and anorexia. Furthermore, many issues and risks to a patient's life, it is may be caused by incorrect treatment. Moreover, misdiagnosis and heavy use of analgesics affect patients' lives. The number of opioid overdoses has increased in recent years in several countries, in part due to increased use of opioids in the management of chronic pain. Between 2010 and 2018, the number of people dying from opioid overdose increased by $120 \%$ in the United States of America (USA), with synthetic opioids accounting for two-thirds of all opioid-related overdose deaths [7]. Despite technological capabilities, the possibility of dealing with pain is poorly done [4,5].

This generally affects patients who have difficulty communicating verbally, as well as adults with cognitive impairment, such as those who have a score of 18 or higher on the Mini Mental Status Examination (MMSE) [49], which indicates moderate to severe dementia [8].Patients who cannot explain their pain experience such infants, toddlers and children, unconscious patients [9]. Based on what mention above, the need to develop an automatic pain recognition system becomes urgent and one day will be the best complement for the current clinical assessment tools [10]. To get better pain assessment and accurate treatment by monitoring pain continuously, it may be more sensitive to trivial changes than basic human observation [11]. In recent decades, automatic pain recognition has led to a huge revolution in research subjects of significant utility. This aspect of medical sciences witnesses a great development based on human machine interaction.

Researchers are constantly striving for the most promising results from automatic pain recognition, viewing it as a convenient method for assessing pain in patients with dementia, brain injuries, younger children, and infants who are unable to communicate their pain or have lost their ability of verbally explain their pain. Like shy patients or old people who think, that pain is an inevitable thing when they get old, so they do not disclose their pain. Moreover, automatic pain assessment provides continuous monitoring for patients so it will not miss any pain indicator, especially this rapid movement that cannot captured by a human observer [12]

APR will contribute to reducing the overcrowding of patients in medical care centers, especially the elderly who are vulnerable to infection with other diseases. Especially through epidemics, like covid-19 via giving the priority of diagnosis for urgent cases. It will not be a replacement for medical staff, as many belief; rather, APR will play the primary role of assisting medical personnel and relieving pressure on them by developing a new method of providing medical diagnosis aligned with unexpected situations, particularly in this case, which requires significant effort and time from them. Automatic pain recognition will contribute to minimizing the usage of analgesics by using them only with signs related to pain. This review as shown in Figure (1) will provide general clarification on the planning of an automatic pain recognition system. Section (2) describes a single model signal, while Section (3) clarifies a multi-modal signal. Then, in sections 4 and 5, it mentions clinical assessment tools and datasets. After all, of this, will clarify the general structure of the automatic pain recognition system and dig deep into each detail. Then will discuss the most important challenges and issues faced by the automatic pain recognition system.

There are many types of signs used as pain indicators by an automatic pain recognition system, such as Electrocardiogram (ECG), Blood Volume Pulse (BVP), and Skin Conductance Level (SCL) which were used by Yaqi, et al. [22], their dataset was collected from (six-subjects for 7-days. When an APR system uses one of these vital signals, it referred to as a single model; when it uses more than one signal, it referred to as a multi-model.

By using behavioral signals such as the work by Lopez, et al. [72], using facial expression as a valid indicator of a patient's level of suffering and proposed Radon Barcodes (RBC) for feature extraction from infants' facial expressions based on the COPE dataset.

Mansor and Rajab [73], proposed a robust system for detecting the signs of pain from infants' faces based on continuous monitoring, Zamzami, et al. [75] proposed pre-training CNNs to extract deep features of pain expressions and working on a dataset of (31indivdual, 3026 images).

In 2018, 2019 [76,77] Adopted facial expression as pain indicator of Traumatic Brain Injured (TBI) patients with UNBCMcMaster dataset. Malara, et al. [85] adaptive body movement in elderly patients with dementia as a pain indicator. Furthermore, research on vocalization as a pain indicator has been conducted, such as the work of Kurth, et al. [87], or Lautenbacher, et al. [88] with work titled Phonetic characteristics of vocalizations during pain. Most of these works will discussed in detail in different sections below.

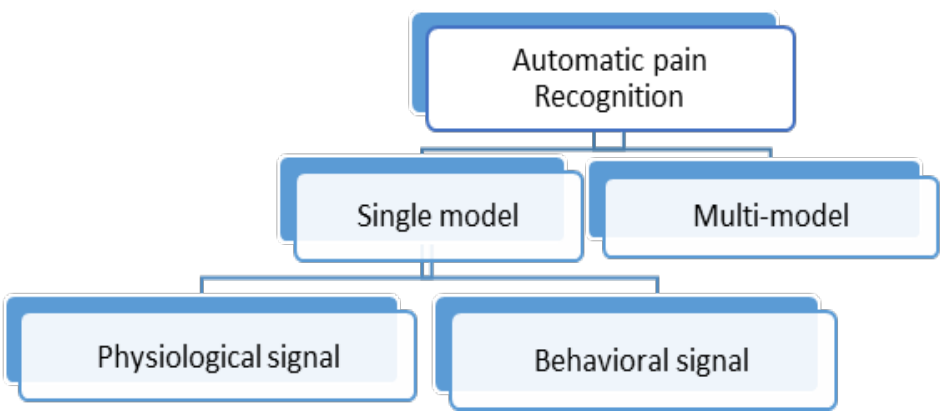

Figure 1: Automatic Pain Recognition planner

\section{Single-Model}

Singular pain-recognition structures may described as systems that use a single type of measure to identify the degree of suffering. These measures include physiological and behavioral. 


\subsection{Physiological Signal}

Physiological signals are among the most critical factors used to identify the degree of suffering from the body's physiological state. It involves important vital signs (ECG, SCL, EMG, EEG, BVP, EDA, Heart Rate, Oxygen Saturation, Pupil Size (Left and Right), Respiration Rate, Skin Temperature, and Urine-Color). Table (1) shows the physiological signal as an indicator of pain.

Yaqi Chu, Xingang Zhao et al. [22], implemented a new method for pain intensity recognition based on multiple physiological signals such as Electrocardiogram (ECG), Blood Volume Pulse (BVP), and Skin Conductance Level (SCL), caused by the external electrical stimulus as shown in Figure (2). Dataset of their work was collected from (six-subjects for 7days). $75 \%$ of specimens implemented as a training set and the rest as a testing set. They used GA (genetic algorithm) as feature extraction and Principal Component Analysis (PCA) as feature reduction. Finally, they used LDA (linear discriminant analysis) as a classifier and then compared its performance with KNN and SVM as shown in Figure (3). The result of pain intensity accuracy with (84.28\%) LDA, (83.94\%) KNN, and (96.47\%) SVM. This proposed system expected to implemented as a daily-use wearable device.

Table 1: Some of physiological signal as indicator of pain

\begin{tabular}{|c|c|c|}
\hline Physiological & Pain indicator & rences \\
\hline $\begin{array}{l}\text { Skin } \\
\text { conductance } \\
\text { (SC) }\end{array}$ & $\begin{array}{l}\text { It altered with the experience of pain. Increased sympathetic outflow pain-related allows } \\
\text { sweat to be transferred through pores on the human skin, as sympathetic excitatory } \\
\text { efferent neurons are the only ones that innervate sweat glands. Sweat changes the } \\
\text { electrical properties of the skin, resulting in a raise in electrical conductivity even sweat } \\
\text { absorbed by the body or allowed to evaporate. }\end{array}$ & {$[11,13,14]$} \\
\hline Blood pressure & $\begin{array}{l}\text { Changes in characteristic of skin conductance due to pain, within increase of heart rate } \\
\text { caused irregular blood pressure in resting time }\end{array}$ & [15] \\
\hline Heart rate $(\mathrm{HR})$ & $\begin{array}{l}\text { Sympathetic stimulation main reasons to major cardiovascular variations, which actually } \\
\text { effect the heartbeat and cause tachycardia, variance in the heart rate and automatic pulse } \\
\text { rate regulatory index, especially pain. Extra pain rises systemic vascular resistance and } \\
\text { volume of stroke also, pain greatly raising low-frequency power, which is calculated by } \\
\text { spectral power analysis. }\end{array}$ & {$[16,17]$} \\
\hline Pupil diameter & Pupil diameter affected by the pain duo to the dilation of the pupil & {$[18,19]$} \\
\hline Brain activity & $\begin{array}{l}\text { Pain affects the metabolic and electrical actions of the brain cortical area EEG } \\
\text { determines the electrical action changes in the brain. fMRI and fNIRS both used to } \\
\text { detect a hemodynamic change in the brain. }\end{array}$ & {$[20,21]$} \\
\hline
\end{tabular}

A

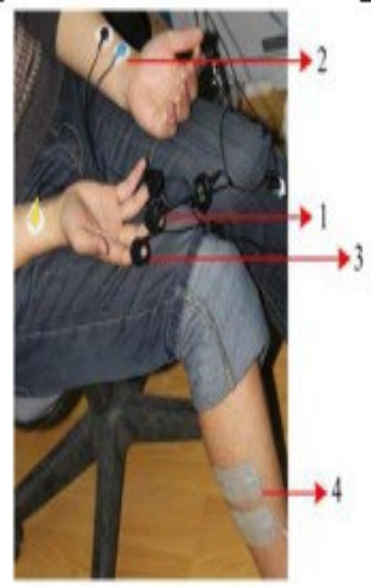

B

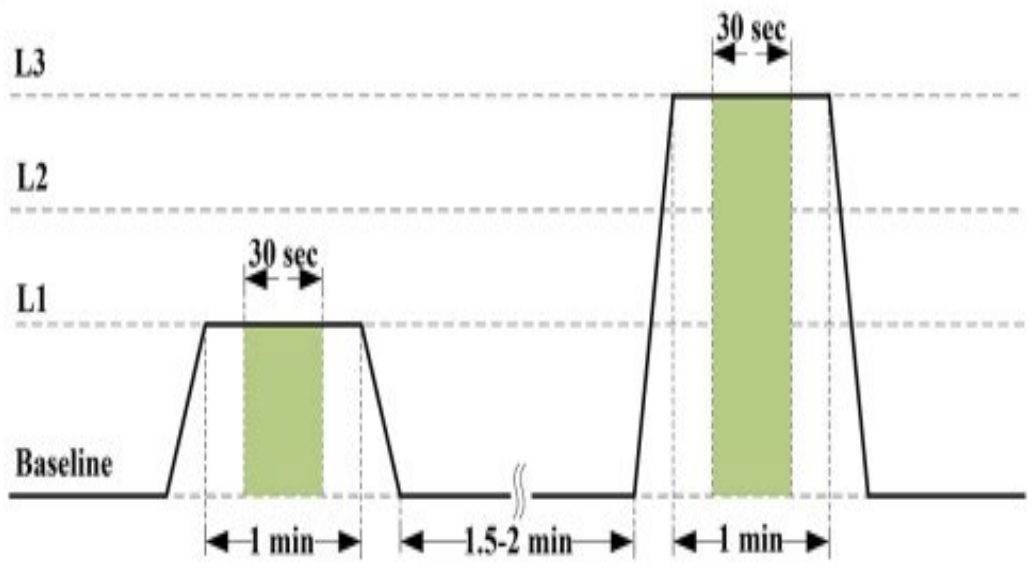

Figure 2: (A) Collecting data of pain. Posture of sensors and electrical stimulation: (1) BVP-Flex/Pro sensor, (2) EKG-Flex/Pro sensor, (3) SC-Flex/Pro sensor, and (4) Electrical stimulation. (B) Pain induction protocol. The stimulus levels are represented by current intensity L1 to L3. The features are extracted from the green window of length $30 \mathrm{~s}$ 


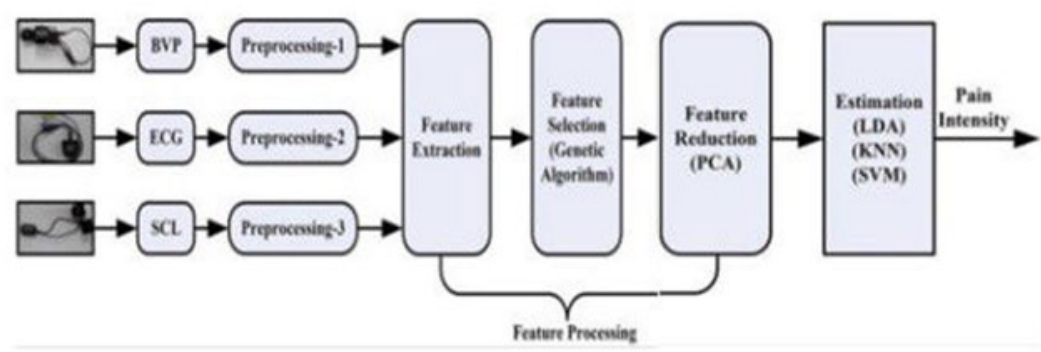

Figure 3: Structure of the pain intensity recognition system

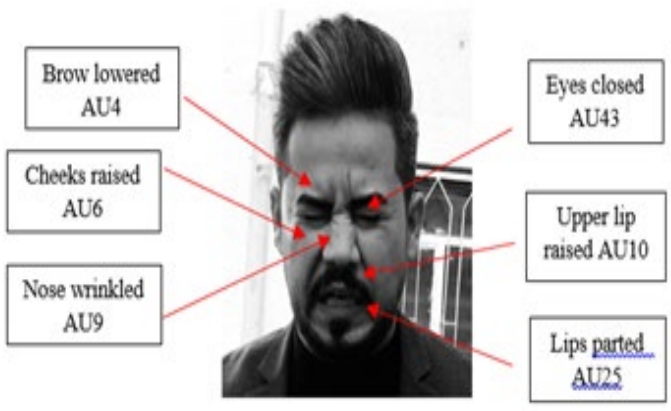

Figure 4: Facial expression related with pain

\subsection{Behavioral Signal}

Any procedure that causes a change in the behavior and attitude of the organism due to stimulation of pain. Pain sensations affect nociceptive excitation; external pain receptors include neurons that are responsive to painful mechanical stimuli, extreme temperature, and chemical stimuli [23]. It includes facial expressions, vocalizations, body movements, changes in interpersonal interactions, mental status change, and changes in activity patterns [24]. As shown below in Table (2), some behavioral factors as pain indicators

Table 2: Behavioral factors as pain indicator

\begin{tabular}{|c|c|c|}
\hline Behavioral & Pain Indicator & References \\
\hline $\begin{array}{c}\text { Facial } \\
\text { Expression }\end{array}$ & $\begin{array}{l}\text { According to recent research, the patient's face is a mirror for her/his inner suffering; } \\
\text { a large number of studies indicate pain from the sequence of acts involving facial } \\
\text { muscle units (AUs) based on FACS. Fig [4] shows exemplary facial reactions } \\
\text { through painful experiences. There is conclusive evidence that the expression of } \\
\text { facial pain is specialized pain that is not only responsive but also distinguishable } \\
\text { from other emotional expressions. }\end{array}$ & $0] \quad[25,27,3$ \\
\hline $\begin{array}{c}\text { Body } \\
\text { Movement }\end{array}$ & $\begin{array}{l}\text { Assessed as a reaction of any action that affects the body, especially pain like rigid, } \\
\text { guarding, and tense, physical aggression, fidgeting, increased pacing/rocking, and } \\
\text { mobility changes such as inactivity or motor restlessness. }\end{array}$ & 0] $[24,31,4$ \\
\hline Vocalization & $\begin{array}{l}\text { When we are in a bad situation, we shout for help as the same when babies feel in } \\
\text { distress or pain, they would cry, so our voices in a different pattern (Moaning, crying, } \\
\text { groaning, sighing, and gasping). Voice nature can noticed in verbal self-report. } \\
\text { Vocalization signals are consider as a part of qualified scales PACSLACF, CPOT, } \\
\text { LACC. }\end{array}$ & $\begin{array}{l}{[24,28,4} \\
1,50]\end{array}$ \\
\hline
\end{tabular}

\section{Multi-Model Signal}

In this approach of pain recognition aspect, researchers attempt to employ more than one physiological and behavioral signal. In [51] Recorded physiological responses (ECG, EMG of, corrugator and zygomaticus, SCL) video (facial expressions, facial skin temperature, and body gestures) and audio data as the results shown below in Table (3). Short-term (phasic) and longer-term (tonic) heat and electrical pain stimulations at different intensities were used on the 134 participants. 
Table 3: Overview on the technical features of the recorded signals and pain stimulation.

\begin{tabular}{|c|c|c|}
\hline $\begin{array}{l}\text { Technical Features } \\
\text { Indicator }\end{array}$ & $\begin{array}{l}\text { Rate of } \\
\text { sampling }\end{array}$ & Characteristics \\
\hline Audio record & (44100) Hertz & Monophonic recording, (MP3/320) kbps \\
\hline $\begin{array}{l}\text { Camera (frontal face } \\
\text { view) }\end{array}$ & (25) Hertz & $\begin{array}{l}\text { Resolution video color: } 1384 \times 1032 \text {, High efficiency video encoded } \\
\text { with libx } 265 \text { (Constant rate factor 16, preset medium) }\end{array}$ \\
\hline Camera (side face view) & (25) Hertz & $\begin{array}{l}\text { Color Resolution of video: } 1620 \times 840 \text {, High efficiency video } \\
\text { encoded with libx265 (Constant rate factor 16, preset medium) }\end{array}$ \\
\hline Thermic Camera & (120.8) Hertz & $\begin{array}{l}\text { Video of Surface temperature : (grayscale MPEG-4-Advanced video } \\
\text { coding encoded with libx264) resolution } 120 \times 160(\mathrm{CRF} 0 \text {, preset } \\
\text { very fast), encoded rate of temperature } 26.5-52.0^{\circ} \mathrm{C} \text { (steps of } 0.1 \text { ) }\end{array}$ \\
\hline Body Camera & (30) Hertz & $\begin{array}{l}\text { Color Resolution of video: } 1500 \times 600 \text {, High efficiency video } \\
\text { encoded with libx265 (Constant rate factor 16, preset medium); } \\
\text { Depth Resolution of video: } 500 \times 200 \text {, lossless encoding }\end{array}$ \\
\hline Skin conductance level & (1000) Hertz & $\begin{array}{l}\text { Hardware filtered via BioPac: } 10 \mathrm{~Hz} \text { Low pass filter, no High pass } \\
\text { filter, no band-stop (with narrow stopband)filter }\end{array}$ \\
\hline Electrocardiogram & (1000)Hertz & $\begin{array}{l}\text { Hardware filtered via BioPac: } 35 \mathrm{~Hz} \text { Low Pass filter, } 0.5 \mathrm{~Hz} \text { High } \\
\text { Pass filter, } 50 \mathrm{~Hz} \text { band-stop with narrow stop band filter }\end{array}$ \\
\hline $\begin{array}{l}\text { Electromyogram } \\
\text { musculus. Trapezius }\end{array}$ & (1000) Hertz & $\begin{array}{l}\text { Hardware filtered via BioPac: } 500 \mathrm{~Hz} \text { Low pass filter, } 10 \mathrm{~Hz} \text { High } \\
\text { Pass filter, no band-stop (with narrow stopband) filter }\end{array}$ \\
\hline
\end{tabular}

Automatic pain assessment based on physiological signals collected by sensors does not meet the desired solution for continuous monitoring. Due to

1. Higher cost because it needs multiple sensors and a complete system to process data.

2. Size and weight of sensor package

3. Most wearable sensors directly connected to the processing device or power supply devices that increase their difficulty to use.

4. Sensor accuracy

5. High complexity microcontroller

6. People, especially those with a bad temper or highly distressed state, refuse to use contact sensors or any uncomfortable device.

7. Sensor systems are vulnerable to damage due to differences in the environment, wrong use, and lack of maintenance.

\section{Clinical Pain Assessment Tools}

Pain management is a clinical mission at the heart of palliation endeavors. The obstacle of this mission is to achieve successful relaxation with fewer side effects and to provide this service to all patients in need of these initiatives. Success in overcoming these challenges requires the definition of the seriousness of the situation, the description of pain syndromes, and the determination of the optimum designation of efficient treatment options, verification of obstacles to the development of efficient methods, verification of solutions to overcome these obstructions, and tracking of results for continual improvement [52]. Clinical assessing tools like self-report and observational scales [9] as shown below in Table (4) do this clinical mission.

Table 4: Clinical assessment tools

\begin{tabular}{|c|c|}
\hline $\begin{array}{c}\text { Self } \\
\text { REPOR } \\
\mathrm{T}\end{array}$ & $\begin{array}{l}\text { Known as the gold standard for pain estimate, especially for those patients who can verbally communicate, there are } \\
\text { some existing different intensity scales based on self-report. Verbal rating scale (VRS). The VRS is a five verbal } \\
\text { categories scale that contains a list of attributes explaining varying degrees of pain severity (no pain, slight pain, } \\
\text { modest pain, serious pain, and very severe pain). It also used to classify the severity of the ache and its features of high } \\
\text { reliability and convergent validity [53]. Numerical rating scale (NRS). } \\
\text { Kindly confirm the strength of existing, best, and worst pain intensity in the last } 24 \text { hrs on a scale from zero, there is no } \\
\text { pain to ten means worst pain ever [54]. Visual analog scale (VAS) put a vertical sign on the line from no pain to very } \\
\text { severe pain to estimate how bad you feel your pain is [55,56]. } \\
\text { Faces pain scale (FPS) is used for an elderly patient with a six-face schematic rating pain indicator of (0-6) [57]. } \\
\text { The wrong baker scale (WBS) similar to FPS but it used for children to help them to explain their pain rating scale } \\
\text { from } 0 \text { (no hurt) to } 10 \text { (hurts worst) [55]. All these scales need a specific degree of cognition and ability to function, } \\
\text { which is not always available. This is a crucial condition to make it assess patient pain intensity with accuracy }\end{array}$ \\
\hline $\begin{array}{c}\text { Observati } \\
\text { onal } \\
\text { SCALE }\end{array}$ & $\begin{array}{l}\text { Obtaining the self-report is an impossible mission. The clinician resorts to accreditation on observational scales. } \\
\text { Various types of scales have been planning to use each group for special medical. } \\
\text { Such as Infants and toddlers (NIPS, FLACC, CRIES, NFCS, N-PASS, and NCCPC-R) [55], [42]. In fragile group with } \\
\text { advanced stage of dementia (PACSLAC, DOLOPLUS2, PAINAD) [29,32,33,36,39,44,58] and for a cognitive } \\
\text { impaired [46,47]. For unconscious patients using observational scales such as (BPS, CPOT, and NVPS) } \\
{[28,45,48,55,59] \text {. A significant amount of previous knowledge and experience is necessary to adjust the accurately. }} \\
\text { Even if highly skilled medical staff can capture pain severity by observation so many times per day, such frequent } \\
\text { observations are likely to neglect some important signs depending on the personality and behavior of patients. } \\
\text { Furthermore, important periods of pain may skip or changes may be observing late by human observation. In contrast, } \\
\text { the automatic system can evaluate suffering persistently and monitors even these flashing movements. }\end{array}$ \\
\hline
\end{tabular}




\section{General Design of Automatic Pain Recognition System (APR)}

Automatic pain recognition system generally consist from multi-stage which is done the pain recognition in sequential process (input, processing and output) implemented in machine learning and computer vision technique. Firstly, the input stage describes data acquisition. Next, the system entered the processing phase to get feature-by-feature extraction and feature selection. Finally, the output stage that is responsible for choice of the type of classifier and getting the result and accuracy rate. All these stages described below and in Figure (5) clarified the general structure of the automatic pain recognition system.

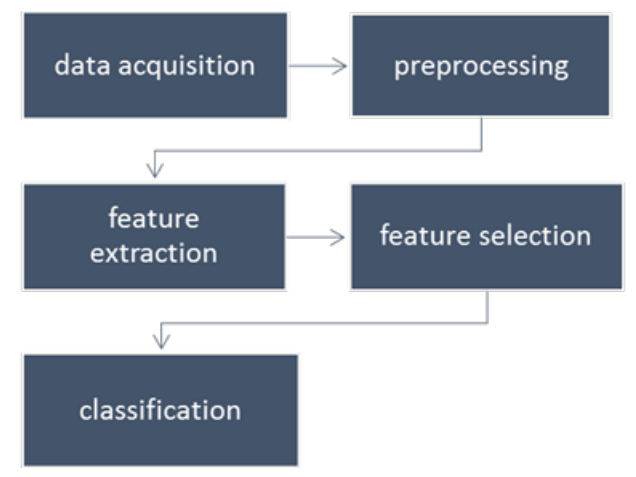

Figure 5: General design of automatic pain recognition

\subsection{Data Acquisition}

The first stage in the automatic pain recognition system, deals with different types of signals such as physiological and behavioral as mentioned in (subsections $2.1,2.2$ ) to provide pain information to the computer. Data obtained by (digital cameras, smartphones, and microphones) from behavioral signs or contact sensors like (wristbands, caps, glasses, t-shirt, and rings) to deal with physical signs. On the other hand, using both in a multimodal system.

\subsection{Preprocessing}

Preprocessing is an important stage in the automatic pain recognition technique because after getting pain information it may be not in standard form and affected by noise, occlusion, and various environmental circumstances. Therefore, the data must be standardized and enhanced before being extracted features.

\subsection{Feature Extraction}

The most important stage in an automatic pain recognition system is feature extraction. It works like zooming in general feature space and collecting the most related features and building a new space with fewer dimensions, completely different from the original space. The efficiency of the automatic pain recognition system depends on the applied technique in this stage.

\subsection{Feature Selection}

When the input data is huge to be processed, here is the crucial role of this stage appear by evaluating a subgroup of the original features is called selecting a feature. The selected features hold the relevant information from the input data so that the optimal goals can accomplished by using this relevant information from the input instead of the full initial data and that leads to minimizing the training time, reducing dimensionality and overfitting.

\subsection{Classification}

A classifier is the last stage in the APR system. When the pain-relevant features putting on the input of this stage, it will work on deciding existing pain or not. The most known classification (Binary, Multi-class, Multi-label, and Imbalanced) classification model and all types of (ML) algorithms can apply here, like (K-Nearest Neighbors, Support Vector Machine, Decision Trees, Logistic Regression, Naïve Bayes, and Random Forest).

\section{Behavioral Signal as Input Data for Automatic Pain Recognition}

As stated in (section 2.2), behavioral signals such as (Body movement, vocalization, and facial expression) could be used as the input data to an automatic pain recognition systems and extracting pain features from them in various painful situations , and ages from neonates to children, adults, and elderly patients. A brief conclusion about the validity of each of the behavioral signals as an indicator of pain provided at the end of this section in table (8). Moreover, which one has a high level of reliability and acceptance in research of pain?

\subsection{Facial Expression}

Facial expression is an important sign of pain assessment (see section 2.2), particularly when the patient losing the ability to communicate their pain, in Figure (6), automatic pain recognition system (APR). When Facial Expressions (FE) as input data. Facial muscular action units (AUs) identified by the Facial Action Coding System (FACS) have been intensively investigated and are extremely reliable as a sensor for detection of facial movements which include relevant pain detection as shown below in table (6). Huge research has adopted FE as a pain assessment tool, facial expression as a valid indicator of a 
patient's level of suffering, Lopez, et A1. [72] proposed Radon Barcodes (RBC) for feature extraction from infants' facial expressions based on the COPE dataset.

Then used the RBC descriptor with Support Vector Machine (SVM) for classification and getting a very promising result of accuracy rate of around 95\%. Mansor and Rajab [73] proposed a robust system also for detecting the signs of pain from infants' faces based on continuous monitoring and tested it under different lighting conditions to guarantee the enduringness of the system. They adopted the Multi-Scale Retinex (MSR) algorithm for extracting lightning invariant facial attributes [74]. Then LBP adopted as feature extraction. Finally, they tested their work with two classifiers (Gaussian and nearest mean) on the COPE dataset and got a very promising accuracy of 90\%. Zamzam, et al. [75] proposed pre-training CNNs to extract deep features of pain expressions from infants face dataset (31indivdual, 3026 images) all CNNs (VGG-F, VGG-M, VGG-S, and VGG-face) executed in MATLAB (MatConvNet). They found that the accuracy of mixing features from both handcraft and deep features got better results, around $93 \%$ and 0.948 AUC. That means transfer learning faster and functional choice than training CNN.

Pain behavior patterns in TBI patients with different levels of awareness are uncharacteristic. As well, changes in face movements can indeed be beneficial in assessing pain in these patients [76, 77] Adopted facial expression as pain indicator of Traumatic Brain Injured (TBI) patients by using viola and jones (VJ) method for face detection and then fed to CNN-LSTM system. Roy, et al. [57] implemented the variety of facial expressions to provide useful information about the severity of patient pain. It offers an effective window for service users who cannot explain their pain levels. By using Gabor filter and Principal Component Analysis (PCA) for feature extraction based on UNBC-McMaster dataset, with two methodologies of classification frame level with an accuracy of $87 \%$ and image level with an accuracy of $95 \%$. Table 5 shows the pain expressions across the lifespan.

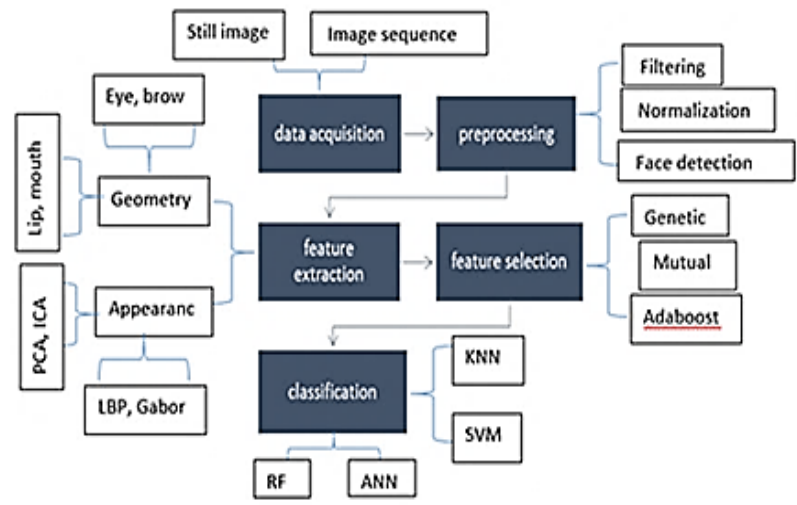

Figure 6: Facial expression as input data for Automatic pain recognition system

Table 5: $\quad$ Pain expression across the lifespan

\begin{tabular}{|c|c|c|}
\hline Lifespan & Facial Expression Action Unit & References \\
\hline Neonate & $\begin{array}{l}\text { Brow bulge } \\
\text { Eye squeeze } \\
\text { Nasolabial furrow, vertical mouth stretch } \\
\text { Lip corner puller } \\
\text { Chin quiver }\end{array}$ & $\begin{array}{l}{[81,83,} \\
84]\end{array}$ \\
\hline Elderly & $\begin{array}{l}\text { cheek raise, Lids tighten (AU 7, AU 6) } \\
\text { lip raiser, Nose wrinkle (AU 10, AU 9) } \\
\text { Lip corner pull (AU12) }\end{array}$ & {$[79,80]$} \\
\hline child & $\begin{array}{l}\text { Brow lower } \\
\text { Eye squeeze, squint, cheek raiser(AU 6) } \\
\text { Nose wrinkle(AU 9), nasolabial furrow, upper lip raiser(AU 10) } \\
\text { Horizontal mouth stretch } \\
\text { Vertical mouth stretch } \\
\text { Flared nostril }\end{array}$ & $\begin{array}{c}{[35,38,} \\
79,80]\end{array}$ \\
\hline Adult & $\begin{array}{l}\text { Brow lower (AU 4) } \\
\text { cheek raise, Lids tighten (AU 7, AU 6) } \\
\text { upper lip raiser, Nose wrinkle, (AU 10, AU 9) Eyes close (AU 43) } \\
\text { Lip corner pull (AU 12). } \\
\text { Horizontal mouth stretch (AU 20) }\end{array}$ & {$[78-80]$} \\
\hline
\end{tabular}

\subsection{Body Movement}

According to this evidence, it may be hard to differentiate neurological disorders from painful symptoms in dementia. Supplemental information was required for authenticating an item. They express their pain in different patterns, such as 
demonstrated that persons with dementia and restlessness had significantly greater pain levels than those without restlessness [37,85]. As expert nurses and caregiver opinion, somebody's movements can be an expression of pain [31]. Table (6) explained some body movements and rate of being as evidence of pain.

\subsection{Vocalization}

Vocalizations are classified as verbal, non-verbal utterances, and breathing. Based on The definition of the American Geriatric Society (AGS) for vocalization is out as a common pain behavior. In the automatic pain recognition system, vocalization considered as an input signal, which contains the following features: moaning, sighing, grunting, groaning, calling out, chanting, asking for help, noisy breathing, and being verbally abusive. Interestingly, the AGS does not characterize crying as verbal communication, but as a mental state modification [86]. Although the researchers had contrasted opinions about depended vocalization stand-alone as a pain indicator, nonetheless, it used to demonstrate the presence of pain whether in people with cognitive impairment, children, and so on $[87,88,89]$. The study on verbalization demonstrated $48.3 \%$ of all children of 4 to 6 years old trying to use verbalizations to communicate about their pain, while the rest $51.7 \%$ did not. More often, older children use verbalizations as pain signs. Researchers suggested that it could related to social factors [90]. Vocalization is also associated with pain in elderly people more often, such as moaning and verbal complaints. There are different patterns of vocalization (see section 2.2) associated with a different type of pain and even with the intensity of pain. Nonetheless, vocalization does not have a common use like facial expression. Below in table (7) discussion about Reliability and Acceptance of behavioral signals as an indicator of pain:

Table 6:Summary for body movement as pain indicator with different rate of evidence

Body movement as signs of pain

Evidence

Walk disturbance; hobble, weakened gait, stumbling,

Tremors; shaking, quivering

Repeated movements; moving back and forth, tossing and turning, flailing/flapping arms, hand movements, rocking

Decline mobility/activity; moving slowly, stopping, freezing, reluctant or refusing to move, lying

down, withdrawal

Reinforcement; act of strengthening like use object for supporting activity

Moderate

Flinching Pacing; attempt to leave/get to another place, reduced or raised wandering

Poor posturing; curling up, going into foetal position, position/weight shift, awkward

sitting/standing/lying, dislocated limbs, contract body, stoop

Rubbing; holding or clutching body part, massages sore area, tactility

Restlessness; fidgeting, agitation

Harshness; restricted mobility, stiffness, clenched hands or fists

Physical offensive; fighting, combativeness, scratching, thrashing, grabbing, hitting, pushing,

kicking, throwing things

Guarding; resisting care, reluctant to be touched, pulling away, protecting body/sore area, not

allowing people near or to be touched

Table 7: Validity of behavioral signals as an indicator of pain: Reliability and Acceptance

Behavioral Signals Reliability and Acceptance

According to the results of this survey, the results ranged from high reliability and accuracy to behavioral change in facial expression and relying on it as a promising tool for pain assessment

Facial

Expression

Body

Movement

Vocalization when compared to behavioral changes such as body movement and vocalization, which faced numerous challenges. like neonate behaviors that refer to pain, children who are shy to translate pain as body movement or vocalization due to social factors, and elderly people with a special disorder which prevents them from interpreting their pain in body movement, or those who consider pain as a normal sign of getting old, so they stopped complaining about their pain.

Based on the 13 categories of body movements in pain research, just five with strong evidence of pain about $(38 \%)$. Also, all this research depends on studying this behavior in special situations such as treatment or diagnosis time and daily activities such as standing, sitting and walking in the place, using a painful treatment procedure to validate behavioral indicators of pain. No studies provide evidence on body movement as an indicator of pain at rest or special times when patients cannot move. The body movement response flinching, on the other hand, may be more common in acute and localized pain and less common in long-term and generalized pain. Furthermore, the study on dementia patients found it difficult to differentiate between normal dementia behavior and behavior that may be due to pain. Whereas other studies on the dementia group discovered the same facial expression as non-dementia patient.

According to expert opinions and the findings of a systematic review into the validity of vocalization as a pain indicator, research on different patterns of vocalization such as crying, groaning, and moaning conducted between [2000-2019] revealed that the majority of studies investigated three or more different patterns of vocalization to find an association with pain. The studies that did not find an association with pain, investigated only one pattern of verbalization or only crying. As a result, they found vocalization could not stand alone as a pain indicator without facial expression or body movement. 


\section{Current Challenges and Problems}

The automatic pain recognition system faces many challenges, starting from collecting data and limitation of samples, so at this point, researchers and scientists should work together to collect as much as possible available data which contains various cases of a patient and under rest, treatment and normal life activity conditions. Then published this data to be available to any research attended to developing an automatic recognition system. Then the most important issue around automatic pain recognition system is being a research topic rarely used in real life. Therefore, physicians must give it more interest and space to get a helpful tool and constant monitoring leads to accurate detection and accurate treatment of pain.

\subsection{Datasets}

The challenges faced by researchers in this scientific area are getting the data, because most pain datasets not shared. Then they start gathering their own data, they will face the trouble of the limited number of contributors. Below in Table (8) where several pain datasets presented and clarify in addition the simulation procedure of collecting the data [9]. Whereas figure (7) shows the most pain datasets used in the studies about pain, which were conducted in the last decade (2009-2019).

Table 8: Pain datasets

\begin{tabular}{|c|c|c|c|}
\hline Database & Participants & Stimulation & \\
\hline $\begin{array}{l}\text { UNBC-McMaster } \\
\text { Shoulder Pain }\end{array}$ & $\begin{array}{l}25 \text { adult patients suffer from } \\
\text { shoulder pain }\end{array}$ & $\begin{array}{l}\text { motion range is } 200 \text { tests under (affected, } \\
\text { unaffected) limbs }\end{array}$ & [43-60] \\
\hline Mint PAIN & $\begin{array}{l}\text { Healthy participant } 20 \text { adults age( } \\
22-42)\end{array}$ & $\begin{array}{l}1600 \text { electrical stimuli of pain in } \\
(4 \text { intensities } \times 2 \text { trials } \times 20 \text { participants })\end{array}$ & {$[61]$} \\
\hline BioVid Heat Pain & $\begin{array}{l}90 \text { healthy adults } \\
\text { (age 20-65) }\end{array}$ & $\begin{array}{l}14 \mathrm{k} \text { heat pain stimuli ( } 90 \text { participants } \times 2 \\
\text { parts } \times 20 \text { repetitions } \times 4 \text { intensities) posed } \\
\text { expression, emotion choice }\end{array}$ & {$[62,63,64]$} \\
\hline BP4D-Spontaneous & $\begin{array}{l}\text { Healthy participant } 41 \text { adults age } \\
(18-29)\end{array}$ & $\begin{array}{l}\text { Cold pressure task ( } 41) \text {; emotion } \\
\text { elicitation }\end{array}$ & {$[65]$} \\
\hline BP4D+ & $\begin{array}{l}\text { Healthy participant } 140 \text { adults age } \\
(18-66)\end{array}$ & $\begin{array}{l}\text { Cold pressure task(140); emotion } \\
\text { elicitation }\end{array}$ & {$[66]$} \\
\hline COPE & $\begin{array}{l}\text { Neonates }(26) \\
\text { age( } 18-36 \text { hours })\end{array}$ & $\begin{array}{l}\text { Heel lancing for blood collection (60); non } \\
\text { painful stimulation }\end{array}$ & {$[67-82]$} \\
\hline YouTube & $\begin{array}{l}\text { Infants } 142 \\
\text { age }(0-12) \text { months }\end{array}$ & immunizations & {$[68]$} \\
\hline IIIT-S ICSD & $\begin{array}{l}\text { Infants } 33 \\
\text { age }(3-24) \text { months }\end{array}$ & $\begin{array}{l}\text { Immunizations and another pain causes; } \\
\text { non painful cry }\end{array}$ & [69] \\
\hline Sense Emotion & $\begin{array}{l}\text { Healthy participant } 44 \text { adults age } \\
\text { (26) }\end{array}$ & $\begin{array}{l}8 \mathrm{k} \text { heat pain ( } 45 \text { participants } \times 2 \text { parts } \times 30 \\
\text { repetitions } \times 3 \text { intensities); emotion choice }\end{array}$ & {$[70]$} \\
\hline Emo Pain & $\begin{array}{l}\text { Chronic lower back pain } 22 \\
\text { patients age }(50) \text { with healthy } \\
\text { participant } 28 \text { controls age }(37)\end{array}$ & physical exercises & [34-71] \\
\hline X-ITE pain & $\begin{array}{l}\text { Healthy participant } 134 \text { adults age } \\
(18-50)\end{array}$ & $\begin{array}{l}24 \mathrm{k} \text { phasic pain and tonic pain ( } 804 \text { ) each } \\
\text { one with (heat and electrical) stimulation, } \\
\text { both by } 3 \text { intensities }\end{array}$ & {$[10]$} \\
\hline
\end{tabular}

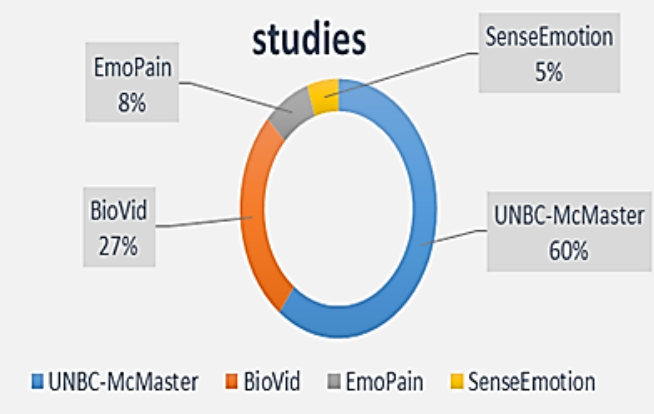

Figure 7: The most pain datasets used in the studies last decade (2009-2019)

\subsection{Challenges of real life Automatic Pain Recognition}

The automatic pain recognition system considered an important research topic. Despite that, in real life, it is suffering from different aspects and this suffering leads to creating a gap between the reality of results and accuracy in research fields and the expectancy of this research to bring it to real-life with the same results and accuracy. In real life, the APR system at first might face hardware complexity due to the difference between the laboratory and clinical environment. Varying in quality and 
resolution of the samples collected from patients. If APR not accepted by the physicians and the rest of the medical staff will not give this system any chance to develop and get the experimental results in real life. On the other hand, pain is a multidimensional experience. Therefore, in real life, multi-methods should work together to reach for the best result. Without a doubt, an automatic pain recognition system is one of these methods for help the medical staff.

\section{Conclusions}

This paper explained the various challenges. Firstly, of designing the automatic pain recognition system and clarifies issues related to assessing pain by using contact sensors. Then the issues with clinical assessment tools all led to more extensive research that should done to improve methods of assessing and treating patients' pain. Due to the real-time challenge, this area of research needs more effort done depending on patient experience-related results. More efforts must be made to collect and make available data to meet the pains of developing and implementing automatic pain recognition system in the real medicine community because even this available data is hard to get due to ethical and legal issues. Finally, the research depends on behavioral signals such as vocalization, body movement, and facial expression as pain indicators. Facial expression demonstrated higher acceptance than other indicators to stand alone as an input signal of the automatic pain recognition system under various conditions, especially with patients who have lost verbal ability.

\section{Author contribution}

All authors contributed equally to this work.

\section{Funding}

This research received no specific grant from any funding agency in the public, commercial, or not-for-profit sectors.

Data availability statement

The data that support the findings of this study are available on request from the corresponding author.

\section{Conflicts of interest}

The authors declare that there is no conflict of interest.

\section{References}

[1] J. Watt-Watson et al. An integrated undergraduate pain curriculum, based on IASP curricula, for six Health Science Faculties, Pain, 110 (2004) 140-148. https://doi.org/10.1016/j.pain.2004.03.019

[2] A. C. de Williams, Facial expression of pain: an evolutionary account, Behav Brain Sci, 25 (2002)439-455. https://doi.org/10.1017/s0140525x02000080

[3] A. C. de C. Williams and K. D. Craig, Updating the definition of pain, Pain, 157 (2016) $2420-2423$. https://doi.org/10.1097/j.pain.0000000000000613

[4] A. Mitchell and B. J. Boss, Adverse effects of pain on the nervous system of newborns and young children: a review of the literature, J. Neurosci. Nurs ., 34 (2002) 228. https://doi.org/10.1097/01376517-200210000-00002

[5] D. C. Turk and R. Melzack, The measurement of pain and the assessment of people experiencing pain, (2011).

[6] H. McQuay, A. Moore, and D. Justins, Fortnightly review: treating acute pain in hospital, BMJ ., 314 (1997) 1531. https://doi.org/10.1136/bmj.314.7093.1531

[7] L. Scholl, P. Seth, M. Kariisa, N. Wilson, and G. Baldwin, Drug and opioid-involved overdose deaths-United States, 2013-2017, Morb. Mortal. Wkly. Rep., 67 (2019) 1419.

[8] J. T. Chibnall and R. C. Tait, Pain assessment in cognitively impaired and unimpaired older adults: a comparison of four scales, Pain, 92 (2001)173-186. https://doi.org/10.1016/s0304-3959(00)00485-1

[9] P. Werner, D. Lopez-Martinez, S. Walter, A. Al-Hamadi, S. Gruss, and R. Picard, Automatic recognition methods supporting pain assessment: A survey, IEEE Trans. Affect. Comput ., (2019). https://doi.org/10.1109/taffc.2019.2946774

[10] P. Werner, A. Al-Hamadi, S. Gruss, and S. Walter, Twofold-Multimodal Pain Recognition with the X-ITE Pain Database, 2019 8th Int. Conf. Affect. Comput. Intell. Interact. Work. Demos, ACIIW 2019, no. September, (2019) $290-296$. https://doi.org/10.1109/ACIIW.2019.8925061

[11] E. E. Benarroch, Pain-autonomic interactions: a selective review, Clin. Auton. Res., 11 (2001) 343-349. https://doi.org/10.1007/bf02292765

[12] B. S. Husebo et al., Herausforderungen bei der erfassung und behandlung von schmerzen bei patienten mit demenzieller erkrankung, Zeitschrift fur Neuropsychol., 23 (2012) 237-246. https://doi.org/10.1024/1016-264X

[13] W. Boucsein, Electrodermal activity. Springer Science \& Business Media, (2012).

[14] M. Benedek and C. Kaernbach, Decomposition of skin conductance data by means of nonnegative deconvolution, Psychophysiology, 47 (2010) 647-658. https://doi.org/10.1111/j.1469-8986.2009.00972.x

[15] M. Sacco et al., The relationship between blood pressure and pain, J. Clin. Hypertens ., 15 (2013) 600-605. https://doi.org/10.1111/jch.12145 
[16] A. J. Terkelsen, H. Mølgaard, J. Hansen, O. K. Andersen, and T. S. Jensen, Acute pain increases heart rate: differential mechanisms during rest and mental stress, Auton. Neurosci ., 121 (2005) 101-109.

https://doi.org/10.1016/j.autneu.2005.07.001

[17] B. M. Appelhans and L. J. Luecken, Heart rate variability and pain: associations of two interrelated homeostatic processes, Biol. Psychol., 77 (2008) 174-182. https://doi.org/10.1016/j.biopsycho.2007.10.004

[18] C. R. Chapman, S. Oka, D. H. Bradshaw, R. C. Jacobson, and G. W. Donaldson, Phasic pupil dilation response to noxious stimulation in normal volunteers: relationship to brain evoked potentials and pain report, Psychophysiology, 36 (1999) 4452. https://doi.org/10.1017/s0048577299970373

[19] E. Szabadi, Modulation of physiological reflexes by pain: role of the locus coeruleus, Front. Integr. Neurosci., 6 (2012) 94. https://doi.org/10.3389/fnint.2012.00094

[20] E. S. D. S. Pinheiro et al. Electroencephalographic patterns in chronic pain: a systematic review of the literature, PLoS One, 11 (2016) e0149085. https://doi.org/10.1371/journal.pone.0149085

[21] B. D. Kussman et al. Capturing pain in the cortex during general anesthesia: near infrared spectroscopy measures in patients undergoing catheter ablation of arrhythmias, PLoS One, 11 (2016) e0158975. https://doi.org/10.1371/journal.pone.0158975

[22] Y. Chu, X. Zhao, J. Han, and Y. Su, Physiological signal-based method for measurement of pain intensity, Front. Neurosci., 11 (2017) 279. https://doi.org/10.3389/fnins.2017.00279

[23] H. J. Kim et al. Racial and ethnic differences in experimental pain sensitivity: systematic review and meta-analysis, Pain, 158 (2017) 194-211. https://doi.org/10.1097/j.pain.0000000000000731

[24] I.-P. Tsai, S. Y.-S. Jeong, and S. Hunter, Pain assessment and management for older patients with dementia in hospitals: an integrative literature review, Pain Manag. Nurs., 19 (2018) 54-71. https://doi.org/10.1016/j.pmn.2017.10.001

[25] T. R. Dawes et al. Objectively measuring pain using facial expression: is the technology finally ready?, Pain Manag., 8 (2018)105-113. https://doi.org/10.2217/pmt-2017-0049

[26] K. Karos, A. C. de C. Williams, A. Meulders, and J. W. S. Vlaeyen, Pain as a threat to the social self: a motivational account, Pain, 159 (2018)1690-1695. https://doi.org/10.1097/j.pain.0000000000001257

[27] M.-H. Tessier, C. Gingras, N. Robitaille, and P. L. Jackson, Toward dynamic pain expressions in avatars: perceived realism and pain level of different action unit orders, Comput. Human Behav., 96 (2019) 95-109. https://doi.org/10.1016/j.chb.2019.02.001

[28] K. K. Sekhon, S. R. Fashler, J. Versloot, S. Lee, and K. D. Craig, Children's behavioral pain cues: Implicit automaticity and control dimensions in observational measures, Pain Res. Manag., (2017) 2017. https://doi.org/10.1155/2017/3017837

[29] M. A. Rahu, M. J. Grap, J. F. Cohn, C. L. Munro, D. E. Lyon, and C. N. Sessler, Facial expression as an indicator of pain in critically ill intubated adults during endotracheal suctioning, Am. J. Crit. care., 22 (2013) $412-422$. https://doi.org/10.4037/ajcc2013705

[30] P. A. Beach, J. T. Huck, M. M. Miranda, K. T. Foley, and A. C. Bozoki, Effects of Alzheimer disease on the facial expression of pain, Clin. J. Pain, 32 (2016) 478-487. https://doi.org/10.1097/ajp.0000000000000302

[31] L. I. Strand et al. Body movements as pain indicators in older people with cognitive impairment: A systematic review, Eur. J. Pain, 23 (2019) 669-685. https://doi.org/10.1002/ejp.1344

[32] S. Chow et al. Pain assessment tools for older adults with dementia in long-term care facilities: a systematic review, Neurodegener. Dis. Manag., 6 (2016) 525-538. https://doi.org/10.2217/nmt-2016-0033

[33] Fry, Margaret, Glenn Arendts, and Lynn Chenoweth,Emergency nurses' evaluation of observational pain assessment tools for older people with cognitive impairment, J. Clin. Nurs., 26 (2017) 9-10: 1281-1290. https://doi.org/10.1111/jocn.13591

[34] L. Cravello et al. Chronic pain in the elderly with cognitive decline: a narrative review, Pain Ther. (2019) 1-13. https://doi.org/10.1007/s40122-019-0111-7

[35] S. D. Subramaniam, B. Doss, L. D. Chanderasekar, A. Madhavan, and A. M. Rosary, Scope of physiological and behavioural pain assessment techniques in children-a review, Healthc. Technol. Lett., 5 (2018)124-129. https://doi.org/10.1049/htl.2017.0108

[36] O. Doody and M. E. Bailey, Pain and pain assessment in people with intellectual disability: issues and challenges in practice, Br. J. Learn. Disabil., 45 (2017) 157-165. https://doi.org/10.1111/bld.12189

[37] D. J. Crellin, D. Harrison, N. Santamaria, and F. E. Babl, Systematic review of the Face, Legs, Activity, Cry and Consolability scale for assessing pain in infants and children: is it reliable, valid, and feasible for use?, Pain, 156 (2015) 2132-2151. https://doi.org/10.1097/j.pain.0000000000000305 
[38] S. E. Thrane, S. Wanless, S. M. Cohen, and C. A. Danford, The assessment and non-pharmacologic treatment of procedural pain from infancy to school age through a developmental lens: a synthesis of evidence with recommendations, J. Pediatr. Nurs., 31 (2016) e23-e32. https://doi.org/10.1016/j.pedn.2015.09.002

[39] M. Mittal, A. Kumar, D. Srivastava, P. Sharma, and S. Sharma, Pain perception: computerized versus traditional local anesthesia in pediatric patients, J. Clin. Pediatr. Dent., 39 (2015) 470-474. https://doi.org/10.17796/1053-4628-39.5.470

[40] M. Atee, K. Hoti, R. Parsons, and J. D. Hughes, Pain assessment in dementia: evaluation of a point-of-care technological solution, J. Alzheimer's Dis., 60 (2017) 137-150. https://doi.org/10.3233/jad-170375

[41] D. Tapp et al.Observational pain assessment instruments for use with nonverbal patients at the end-of-life: a systematic review, J. Palliat. Care., 34 (2019) 255-266. https://doi.org/10.1177/0825859718816073

[42] G. Zamzmi, C.-Y. Pai, D. Goldgof, R. Kasturi, Y. Sun, and T. Ashmeade, Automated pain assessment in neonates, in Scandinavian Conference on Image Analysis, (2017) 350-361. http://dx.doi.org/10.1007/978-3-319-59129-2 30

[43] M. Kunz, K. Prkachin, PE. Solomon, S. Lautenbacher, Faces of clinical pain: inter-individual facial activity patterns in shoulder pain patients, J. Pain., 25 (2021) 529-540. https://doi.org/10.1002/ejp.1691

[44] S. M. G. Zwakhalen, J. P. H. Hamers, H. H. Abu-Saad, and M. P. F. Berger, Pain in elderly people with severe dementia: a systematic review of behavioural pain assessment tools, BMC Geriatr., 6 (2006) 1-15.

[45] K. Herr, P. J. Coyne, M. McCaffery, R. Manworren, and S. Merkel, Pain assessment in the patient unable to self-report: position statement with clinical practice recommendations, Pain Manag. Nurs., 12 (2011) $230-250$. https://doi.org/10.1016/j.pmn.2011.10.002

[46] A. H. van Dalen-Kok et al.Pain Assessment in Impaired Cognition (PAIC): content validity of the Dutch version of a new and universal tool to measure pain in dementia, Clin. Interv. Aging., 13 (2018). https://doi.org/10.2147\%2FCIA.S144651

[47] M. Kunz et al. The Pain Assessment in Impaired Cognition scale (PAIC15): A multidisciplinary and international approach to develop and test a meta-tool for pain assessment in impaired cognition, especially dementia, Eur. J. Pain., 24 (2020)192-208. https://doi.org/doi: 10.1002/ejp.1477

[48] J. C. Solodiuk, Parent described pain responses in nonverbal children with intellectual disability, Int. J. Nurs. Stud., 50 (2013) 1033-1044. https://doi.org/10.1016/j.ijnurstu.2012.11.015

[49] Y. Takai, N. Yamamoto-Mitani, A. Ko, and M. V Heilemann, Differences in Pain Measures by Mini-Mental State Examination Scores of Residents in Aged Care Facilities: Examining the Usability of the Abbey Pain Scale-Japanese Version, Pain Manag. Nurs ., 15 (2014) 236-245. https://doi.org/ 10.1016/j.pmn.2012.09.004

[50] F. J. Symons, B. Byiers, R. Tervo, and A. Beisang, Parent reported pain in rett syndrome, Clin. J. Pain., 29 (2013) 744. https://doi.org/10.1097/ajp.0b013e318274b6bd

[51] S. Gruss et al. Multi-modal signals for analyzing pain responses to thermal and electrical stimuli, J. Vis. Exp., (2019) 146, (2019). https://doi.org/10.3791/59057

[52] E. Laures, C. LaFond, K. Hanrahan, N. Pierce, H. Min, and A. M. McCarthy, Pain assessment practices in the pediatric intensive care unit, J. Pediatr. Nurs., 48 (2019) 55-62. https://doi.org/10.1016/j.pedn.2019.07.005

[53] D. S. Tsze, C. L. von Baeyer, V. Pahalyants, and P. S. Dayan, Validity and reliability of the verbal numerical rating scale for children aged 4 to 17 years with acute pain, Ann. Emerg. Med., 71 (2018) 691-702. https://doi.org/10.1016/j.annemergmed.2017.09.009

[54] O. Karcioglu, H. Topacoglu, O. Dikme, and O. Dikme, A systematic review of the pain scales in adults: which to use?, Am. J. Emerg. Med., 36 (2018) 707-714. https://doi.org/10.1016/j.ajem.2018.01.008

[55] D. Freund and B. Bolick, Assessing a Child's, 119 (2019).

[56] Z. Alizadeh, A. Paymard, A. Khalili, and H. Hejr, A systematic review of pain assessment method in children, Ann. Trop. Med. Public Heal., 10 (2017) 847. https://doi.org/10.4103/ATMPH.ATMPH $155 \quad 17$

[57] E. J. Kim and M. T. Buschmann, Reliability and validity of the Faces Pain Scale with older adults, Int. J. Nurs. Stud., 43 (2006) 447-456. https://doi.org/10.1016/j.ijnurstu.2006.01.001

[58] H. M. Rostad, I. Utne, E. K. Grov, M. Puts, and L. Halvorsrud, Measurement properties, feasibility and clinical utility of the Doloplus-2 pain scale in older adults with cognitive impairment: a systematic review, BMC Geriatr., 17 (2017) 1-28. https://doi.org/10.1186/s12877-017-0643-9

[59] S. Rijkenberg, W. Stilma, H. Endeman, R. J. Bosman, and H. M. Oudemans-van Straaten, Pain measurement in mechanically ventilated critically ill patients: behavioral pain scale versus critical-care pain observation tool, J. Crit. Care., 30 (2015) 167-172. https://doi.org/10.1016/j.jcrc.2014.09.007 
[60] P. Lucey, J. F. Cohn, K. M. Prkachin, P. E. Solomon, and I. Matthews, Painful data: The UNBC-McMaster shoulder pain expression archive database, in 2011 IEEE International Conference on Automatic Face Gesture Recognition (FG), (2011) 57-64.

[61] M. A. Haque et al. Deep multimodal pain recognition: a database and comparison of spatio-temporal visual modalities, in 2018 13th IEEE International Conference on Automatic Face Gesture Recognition (FG 2018) (2018), $250-257$. https://doi.org/10.1109/FG.2018.00044

[62] S. Walter et al. The biovid heat pain database data for the advancement and systematic validation of an automated pain recognition system, in 2013 IEEE international conference on cybernetics (CYBCO), (2013), 128-131. https://doi.org/10.1109/CYBConf.2013.6617456

[63] L. Zhang et al. BioVid Emo DB': A multimodal database for emotion analyses validated by subjective ratings, in 2016 IEEE Symposium Series on Computational Intelligence (SSCI), (2016) 1-6. https://doi.org/10.1109/SSCI.2016.7849931

[64] P. Werner, A. Al-Hamadi, R. Niese, S. Walter, S. Gruss, and H. C. Traue, Towards pain monitoring: Facial expression, head pose, a new database, an automatic system and remaining challenges, in Proceedings of the British Machine Vision Conference, (2013) 1-13. http://dx.doi.org/10.5244/C.27.119

[65] X. Zhang et al. Bp4d-spontaneous: a high-resolution spontaneous $3 \mathrm{~d}$ dynamic facial expression database, Image Vis. Comput., 32 (2014) 692-706. https://doi.org/10.1016/j.imavis.2014.06.002

[66] Z. Zhang et al. Multimodal spontaneous emotion corpus for human behavior analysis, in Proceedings of the IEEE Conference on Computer Vision and Pattern Recognition, (2016) 3438-3446. https://doi.org/10.1109/CVPR.2016.374

[67] S. Brahnam, C.-F. Chuang, F. Y. Shih, and M. R. Slack, SVM classification of neonatal facial images of pain, in International Workshop on Fuzzy Logic and Applications, (2005), 121-128. http://dx.doi.org/10.1007/11676935 15

[68] D. Harrison et al. Too many crying babies: a systematic review of pain management practices during immunizations on YouTube, BMC Pediatr., 14 (2014) 1-8. https://doi.org/10.1186/1471-2431-14-134

[69] V. K. Mittal, Discriminating the infant cry sounds due to pain vs. discomfort towards assisted clinical diagnosis, in 7th Workshop on Speech and Language Processing for Assistive Technologies, SLPAT, (2016) 7-42. https://doi.org/10.21437/SLPAT.2016-7

[70] M. Velana et al. The senseemotion database: A multimodal database for the development and systematic validation of an automatic pain-and emotion-recognition system, in IAPR Workshop on Multimodal Pattern Recognition of Social Signals in Human-Computer Interaction, (2016) 127-139. http://dx.doi.org/10.1007/978-3-319-59259-6_11

[71] M. S. H. Aung et al. The automatic detection of chronic pain-related expression: requirements, challenges and the multimodal EmoPain dataset, IEEE Trans. Affect. Comput., 7 (2015) 435-451. https://doi.org/10.1109/taffc.2015.2462830

[72] A. Martínez López, F. A. Pujol, and H. Mora, Application of texture descriptors to facial emotion recognition in infants, Appl. Sci., 10 (2020) 1115. https://doi.org/10.3390/app10031115

[73] M. N. Mansor and M. N. Rejab, A computational model of the infant pain impressions with Gaussian and nearest mean classifier, in 2013 IEEE International Conference on control system, computing and engineering, (2013) $249-253$. http://dx.doi.org/10.1109/ICCSCE.2013.6719968

[74] D. J. Jobson, Z. Rahman, and G. A. Woodell, A multiscale retinex for bridging the gap between color images and the human observation of scenes, IEEE Trans. Image. Process., 6 (1997) 965-976. https://doi.org/10.1109/83.597272

[75] G. Zamzmi, D. Goldgof, R. Kasturi, and Y. Sun, Neonatal pain expression recognition using transfer learning, arXiv Prepr.arXiv1807.01631(2018). https://doi.org/10.48550/arXiv.1807.01631

[76] R. Nazari, H. S. Nia, S. P. Sharif, K. Allen, and A. Yaghoobzadeh, Which facial movements are pain indicators of patients with traumatic brain injury?, (2019).

[77] C. M. A. Ilyas, M. A. Haque, M. Rehm, K. Nasrollahi, and T. B. Moeslund, Facial expression recognition for traumatic brain injured patients, in International Conference on Computer Vision Theory and Applications, (2018) 522-530. https://doi.org/10.5220/0006721305220530

[78] N. L. Gallant and T. Hadjistavropoulos, Experiencing pain in the presence of others: A structured experimental investigation of older adults, J. Pain, 18 (2017) 456-467. https://doi.org/10.1016/j.jpain.2016.12.009

[79] M. Kunz, D. Meixner, and S. Lautenbacher, Facial muscle movements encoding pain — a systematic review, Pain, 160 (2019) 535-549. https://doi.org/10.1097/j.pain.0000000000001424

[80] K. D. Craig, K. M. Prkachin, and R. E. Grunau, The facial expression of pain., (2011).

[81] G. Zamzmi, R. Kasturi, D. Goldgof, R. Zhi, T. Ashmeade, and Y. Sun, A review of automated pain assessment in infants: features, classification tasks, and databases, IEEE Rev. Biomed. Eng., $11 \quad$ (2017) 77-96. https://doi.org/10.1109/rbme.2017.2777907 
[82] J. Yan et al. FENP: A Database of Neonatal Facial Expression for Pain Analysis, IEEE Trans. Affect. Comput., (2020). https://doi.org/10.1109/taffc.2020.3030296

[83] M. Awais et al. Novel framework: face feature selection algorithm for neonatal facial and related attributes recognition, IEEE Access, 8 (2020) 59100-59113. https://doi.org/10.1109/access.2020.2982865

[84] J. Egede, M. Valstar, M. T. Torres, and D. Sharkey, .Automatic neonatal pain estimation: An acute pain in neonates database, in 2019 8th International Conference on Affective Computing and Intelligent Interaction (ACII), (2019) 1-7. https://doi.org/10.1109/ACII.2019.8925480

[85] A. Malara et al. Pain assessment in elderly with behavioral and psychological symptoms of dementia, J. Alzheimer's Dis., 50 (2016) 1217-1225. https://doi.org/10.3233/jad-150808

[86] A. Corbett et al. An international road map to improve pain assessment in people with impaired cognition: the development of the Pain Assessment in Impaired Cognition (PAIC) meta-tool, BMC Neurol., 14 (2014) 1-14. https://doi.org/10.1186/s12883-014-0229-5

[87] E. Kurth, H. P. Kennedy, E. Z. Stutz, A. Kesselring, I. Fornaro, and E. Spichiger, Responding to a crying infant-You do not learn it overnight: A phenomenological study, Midwifery, $30 \quad$ (2014) 749. https://doi.org/10.1016/j.midw.2013.06.017

[88] S. Lautenbacher, M. Salinas-Ranneberg, O. Niebuhr, and M. Kunz, Phonetic characteristics of vocalizations during pain, Pain Manag., 9 (2019) 569-582. https://doi.org/10.1097/pr9.0000000000000597

[89] J. V Pergolizzi, R. B. Raffa, A. Paladini, G. Varrasi, and J. A. LeQuang, Treating pain in patients with dementia and the possible concomitant relief of symptoms of agitation, Pain Manag., 9 (2019) 569-582. https://doi.org/10.2217/pmt-2019$\underline{0024}$

[90] L. M. L. Helmer et al. Crying out in pain-A systematic review into the validity of vocalization as an indicator for pain, Eur. J. Pain., 24 (2020) 1703-1715. https://doi.org/10.1002/ejp.1623 